\title{
Root system modifications by nursery culture reflect on post-planting growth and development of coniferous seedlings ${ }^{1}$
}

\author{
by Marek J. Krasowski
}

A decade of the author's work evaluating effects of nursery culture on root system development in coniferous seedlings is reviewed. The studies include the evaluation of mechanical stability of young trees grown from different types of planting stock, root system deformations resulting from nursery culture, effects of mechanical and chemical pruning on root system development, hydraulic properties of the roots, and post-planting growth performance.

Key words: root pruning, containerized stock, root

L'auteur a révisé une décennie de ses travaux sur l'évaluation des effets de la culture en pépinière sur le développement du système racinaire des semis de conifères. Les études comprennent l'évaluation de la stabilité mécanique des jeunes arbres provenant de différents types de stock de plantation, les déformations du système racinaire provoquées par la production en pépinière, les effets de l'élagage mécanique et chimique sur le système racinaire, les propriétés hydrauliques des racines et la performance de la croissance après plantation.

\section{Introduction}

Much of the research I was involved in during the 1990s addressed the relationship between root system development in the nursery and the post-planting performance of coniferous seedlings. In those years, I worked as a research scientist for the British Columbia Ministry of Forests, Research Branch. This article reviews already published material enriched by results that have not been released before. For already published studies, only these aspects of the methodology that are critical to the understanding of the purpose, approach, and conclusiveness of the presented research are included. More detailed descriptions can be found in referenced articles. The results that have not been published are supported by a brief description of the methods necessary for understanding how the work was conducted. There is a considerable literature on the topics covered in this paper but it is not intended to be a literature review. Typically, individual research papers focus on single aspects of the root system development in seedlings. The purpose of this article is to show how the root system development in the nursery influences various aspects of post-planting performance.

\section{The Stability of Juvenile Lodgepole Pine}

In 1990, the transition from bare-root nursery culture to the production of seedlings in containers was well advanced in British Columbia (Brazier 1991). The juvenile instability of lodgepole pine (Pinus contorta Dougl.) was reported from Sweden (Lines 1980) as well as from British Columbia (Burdett 1979, Burdett et al. 1986). It was known that nursery culture modified root system development and, consequently, the root systems of planted trees differed morphologically from those of naturally regenerated trees (Coutts 1983, 1990). These modifications were particularly troublesome for pines (Burdett 1978, 1979; Burdett et al. 1986). Although pines may outgrow

\footnotetext{
${ }^{1}$ Presentation to the Canadian Institute of Forestry, North Bay, Ontario, October 2, 2002.

${ }^{2}$ Faculty of Forestry and Environmental Management, University of New Brunswick, Mail Bag 44 555, Fredericton, New Brunswick E3B 6C2. E-mail: marek@unb.ca
}

the juvenile instability (Burdett 1979; Persson 1978, 1982), the long-term effects of poor anchorage at young age may include a crooked trunk, declining growth performance, reduced quality and/or quantity of recoverable wood, and weaker anchorage at maturity due to the displacement of the gravity centre (Lines 1980). Linström (1990) reported that container types used in the nursery significantly affected the

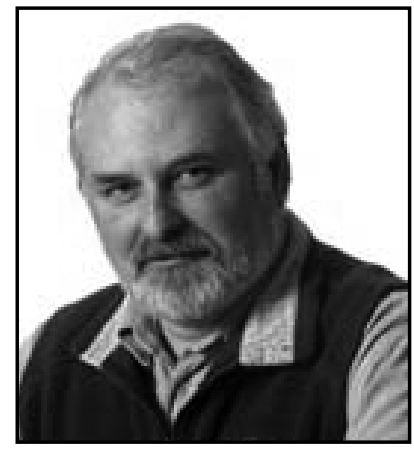

Marek J. Krasowski stability of young stands of Scots pine (Pinus sylvestris L.) in Sweden. In British Columbia, the instability problem was especially common on sites with fine-textured soils (Burdett et al. 1986). However, it was unknown how the strength of anchorage differed among trees planted from different stock types and emerging from the juvenile stage of development.

A study examining the mechanical stability of lodgepole pine was conducted in the early 1990s (Krasowski et al. 1996a). Six sites located in the central interior of British Columbia were included in this work, providing an opportunity to examine how factors such as stock type, spacing at planting, and the tree position (slope versus flat ground) affected tree stability. Although no formal testing of the effects of the soil type was made, the site-to-site variation in tree stability clearly indicated that the properties of the soil strongly influenced tree anchorage, with coarse, sandy soil providing weakest anchorage. Unsurprisingly, tree anchorage strength declined with increasing density of trees and was weaker on slopes than on flat ground (Krasowski et al. 1996a). Results from two sites were most relevant to the topic of this paper. One site, located near Quesnel, B.C was a research site planted 11 years earlier. The original experiment (Clarke and Winter 1986) included various stock types planted in rows of 80 trees in each of the five blocks established. Discontinued stock types (for example, Walter's bullets) were ignored, but three stock types-1) bare-root (BR), 2) hard-wall 
polystyroblock (PSB), and 3) hard-wall polystyroblock painted for chemical root pruning $\left(\mathrm{PSB}_{\mathrm{Cu}}\right)^{3}$-were included in the study. The BR was planted as a two-year-old stock while the container-grown stocks were $1+0$. Four randomized blocks were used in the study and 12 trees of each stock type were randomly chosen in each block (total of 48 trees per stock type) for testing, but the trees were accepted only if their dimensions (height and DBH) were close to the grand mean (all trees in rows representing each stock type were measured in the four blocks, mean heights were about $5.9 \mathrm{~m}$, mean DBH about $0.07 \mathrm{~m}$ ). Tops of the trees were cut off two meters above the ground and the trees were pulled with a steel rope attached below the cut and fed through a hand-operated tirfor winch anchored at the base of another tree (anchor trees were excluded from testing). The pulling force was measured with a dynamometer, the exact height of the rope attachment and the distance to the anchor tree were determined and used for calculating the turning moment. Two forces were recorded - one at tree destabilization (a perceivable movement of the root/soil plate) and another at complete uprooting. Equal numbers of trees were pulled to each cardinal direction.

The analysis of variance showed a nearly significant effect of the stock type (p 0.08) on the resistance to destabilization with the chemically pruned stock being the most resistant. The stock types were not significantly different in their resistance to complete uprooting. However, several trees of the $\mathrm{PSB}_{\mathrm{Cu}}$ snapped during the test and the maximum forces recorded at breaking underestimated the actual resistance of these trees. To account for this, the trees were categorized into four classes of anchorage strength. This was done for destabilization and for complete uprooting because a few trees broke before they destabilized. The percentages of trees per category for the three stock types are shown in Table 1. An ordinal response model using a logistic scale (SAS Institute Inc. 1990) was used for analysis of the data presented in Table 1 . The trees in the $\mathrm{PSB}_{\mathrm{Cu}}$ tended to be in the stronger-tree (more difficult to destabilize) categories. While the stock type effect would not be considered as statistically significant ( $\mathrm{p} 0.08$ ), it was not far from being significant (when $\alpha$ was defined at 0.05 ). For the resistance to complete uprooting, BR trees tended to be in the stronger categories (p 0.09). It can be concluded from the above that chemical root pruning of hard-wall container stock increased the strength of anchorage somewhat, compared to non-pruned hard-wall container stock and to the bare-root stock.

In the course of the study, BR stock was compared to PSB on three sites, including this one, and on two sites the two stock types were not significantly different from each other but on the third site the BR was very significantly more difficult to destabilize and uproot than the PSB (Krasowski et al. 1996a; please note that an erratum was published in 1997 to correct contents of one table in the original paper). Despite the observed inconsistency, it could be said that the transition from bare-root culture of lodgepole pine to container stock production did not, in those days, improve the strength of anchorage. More recently, however, most of pine planted in B.C. is chemically root pruned and larger than the 211-type container cavities are typically used. Hence, the stability of trees on more recently planted sites can be expected to be greater than in trees planted about 20 years ago.

${ }^{3}$ PSB 211, produced by Beaver Plastic Limited, Edmonton, Alberta. The containers for chemical root pruning were custom-coated with latex paint containing a copper salt.
In static tests of stability, the resistance to destabilization may be more important to the evaluation of the anchorage strength than the resistance to complete uprooting. The natural uprooting typically involves a dislodgement of the entire root plate (Deans and Ford 1983). Uprooting a tree by pulling involves a considerable force required to move the root system through the soil and it is possible that root system deformations could actually increase the force required for a complete uprooting of a tree. Testing mechanical stability by pulling trees with a winch gives an estimate of the firmness of tree anchorage that is likely better related to the forces exerted by snow loads than by winds. Winds cause the trees to sway but the rocking movement and alternating changes in force loads are not mimicked in the static tests of stability using the unidirectional pulling force.

An interesting question to ask would be how the anchorage strength of planted trees with roots modified by nursery culture and planting compares to naturally regenerated trees. Two of the sites in the discussed study (Krasowski et al. 1996a) included such comparisons but the confounding factor was the difference in the density of the naturally regenerated trees versus the planted trees. Root systems of the tested trees were recovered for symmetry evaluation and while the naturally regenerated trees had more symmetrical root systems, they had grown at a greater density than the planted trees and, having relatively small root systems, were destabilized and uprooted much easier than planted trees of similar above-ground sizes. However, the anchorage strength of the naturals improved remarkably only a year after thinning. Evaluating the relationship between the distribution of roots and the anchorage strength determined by testing was a complex and difficult task. Preliminary analysis of this kind, based on the currently discussed study, was made and presented at the Nursery Association Meeting in Penticton, B.C. (Krasowski et al. 1993) but the results of these analyses only indicated the need for more time and resources to tackle the problem, none of which was freely available at that time. Interestingly, it was determined that taproots in lodgepole pine were often rudimentary even in naturally regenerated trees. The presence or absence of a taproot had no significant relationship to the strength of anchorage, which is dependent on the numbers, sizes, and distribution of the lateral and sinker roots.

One of the sites included in the study contained an interesting experiment in which six- to eight-week old lodgepole pine seedlings raised in peat blocks were planted before the roots emerged from the growing medium. These seedlings were planted on the same site, at the same time, and same spacing as PSB 211 seedlings of the same seed source ${ }^{4}$. Due to heterogeneity of the soil on the site, the original experimental design was not followed. Instead, a completely randomized sample of 36 trees per stock type was tested 11 years after planting, with the same size criteria for acceptance as on the other sites - the trees had to be about the grand mean in height and DBH. The two stock types were found to be very significantly different from each other in the analysis of variance for destabilization ( $p$ 0.0001) and complete uprooting (also $\mathrm{p}$ 0.0001) with trees from the peatgerminated seedlings (PTG) being much more resistant than those from the PSB stock (Krasowski et al. 1996a, 1997). Although no trees were broken in tests on this site, the placing of trees

${ }^{4}$ Burdett, A.N. 1979. Field trial with six- to eight-week old lodgepole pine seedlings raised in peat blocks. Work plan, experimental project 746.32, B.C. Ministry of Forests, Research Branch, Victoria, B.C., unpublished. 
Table 1. Percentages of trees in different anchorage strength categories by turning moments (in kNm) at destabilization and at complete uprooting for three stock types: bare-root (BR), hard-wall polystyroblock (PSB), and hard-wall polystyroblock with chemical root pruning (PSB ${ }_{\mathrm{Cu}}$ ) tested 11 years after planting on the Jack Fire site near Quesnel, B.C (data from Krasowski et al. 1996a). Turning moments in kNm, lower range values in each category are inclusive.

\begin{tabular}{|c|c|c|c|c|c|c|c|c|}
\hline \multirow[b]{2}{*}{ Stock } & \multicolumn{4}{|c|}{ Categories by destabilization } & \multicolumn{4}{|c|}{ Categories by complete uprooting } \\
\hline & $\begin{array}{c}\text { weakest } \\
<5\end{array}$ & $\begin{array}{c}\text { weak } \\
5>7.5\end{array}$ & $\begin{array}{c}\text { fair } \\
7.5>10\end{array}$ & $\begin{array}{c}\text { strong } \\
>10\end{array}$ & $\begin{array}{c}\text { weakest } \\
<8\end{array}$ & $\begin{array}{c}\text { weak } \\
8>12\end{array}$ & $\begin{array}{c}\text { fair } \\
12>16\end{array}$ & $\begin{array}{c}\text { strong } \\
>16\end{array}$ \\
\hline BR & $48 \%$ & $25 \%$ & $15 \%$ & $12 \%$ & $10 \%$ & $35 \%$ & $32 \%$ & $23 \%$ \\
\hline PSB & $55 \%$ & $20 \%$ & $8 \%$ & $17 \%$ & $22 \%$ & $30 \%$ & $30 \%$ & $18 \%$ \\
\hline $\mathrm{PSB}_{\mathrm{Cu}}$ & $37 \%$ & $23 \%$ & $15 \%$ & $25 \%$ & $17 \%$ & $30 \%$ & $23 \%$ & $30 \%$ \\
\hline
\end{tabular}

into categories of resistance (Table 2) and analysing the data in an ordinal response model with a logistic scale gave the same outcome of the analysis as ANOVA did. This showed clearly that, at equal spacing, trees in which root system development was not modified in the nursery developed stronger anchorage than the trees planted from hard-wall container stock (Table 2). Trees on this site, although of about the same age, were smaller and easier to uproot than trees sampled from the previously described site, hence the ranges of categories were defined differently than those in Table 1 . This difference was considered resulting from different soil structural characteristics and richness of the site (the smaller size of the trees indicating a poorer site), confirming Fraser's (1962) conclusion that the physical characteristics of the soil significantly contribute to the attainment of root form and the mechanical stability of trees.

\section{Further Studies on Root Systems of Lodgepole Pine Seedlings}

Chemical root pruning was rapidly spreading through B.C. nurseries in the early 1990s as reports of improvements to the root form of container-grown trees by chemical pruning started to appear (for example, Wenny and Woollen 1989, Winter and Low 1990). The report by Winter and Low (1990) caught my attention because it compared PSB 211 seedlings that were not root-pruned to chemically pruned and manually pruned (to various extents) seedlings. The authors concluded that seedlings with chemically pruned roots developed the best root system form but it was one of the manual pruning treatments that produced best growth performance. This focused my attention on mechanical root pruning of container-grown seedlings. Parviainen and Tervo (1989) presented a new method of seedling production in a peat board resting in a reusable plastic tray with crated bottom and slotted sides allowing for mechanical pruning of roots by cutting through the peat board. This produced box-pruned root systems embedded in the peat. The system was similar to that described by Burdett (1981). I requested and received from the Finnish manufacturer (Kekkila Vapo Oy) tray and peat board samples that were subsequently used in several trials described here. Although these seedlings were not grown individually in containers or single root cavities, I considered them to be container-grown because of the artificial growing medium, the containment in the plastic trays, and a nursery culture typical for the production of the container stock.

The question leading to the initiation of another study was how different modifications of the root system development in the nursery affect post planting performance, root system deformations, the stem (main axis) lean, and its crookedness. The study compared three different stock types of lodgepole pine: the hard-wall container stock without chemical root pruning (PSB 415B), with chemical root pruning (PCT 415B, the styroblocks were commercially prepared for root pruning at manufacture), and the box-pruned seedlings (Vapo). The Vapo trays were $80 \mathrm{~mm}$ deep and provided the density of 400 plants $/ \mathrm{m}^{2}$. The polystyroblocks had the cavity diameter of $35 \mathrm{~mm}$, depth $149 \mathrm{~mm}$, volume $93 \mathrm{~mL}$, density of 527 plants $/ \mathrm{m}^{2}$ and were chosen because, among different styroblocks used in B.C., they provided the closest (albeit not identical) plant density to that of the Vapo. To reduce a potential effect of spacing on post-planting performance, seedlings produced for the experiment were sorted and culled such that randomly selected samples of 50 seedlings per treatment were not significantly different (at $\alpha=0.05$ ) for height and root collar diameter (RCD) at the time of planting. Two seedlots (\#8956 and \#8624) of lodgepole pine from Prince George area (elevations of 800 and $880 \mathrm{~m}$ ) were used. All seedlings were sown in late March 1992 and lifted at the end of the growing season for freezer storage and spring planting. During nursery culture, the roots of Vapo seedlings were cross-pruned with an electric knife twiceat the height of about $10 \mathrm{~cm}$ and again three weeks before lifting allowing for root healing but also for separating individual seedlings.

Two trials were initiated in 1992. A small trial was established in a coarse sandy loam of an old nursery bed at Red Rock Research Station, Prince George, B.C. The PCT 415B seedlings came either from brand new styroblocks (PCT-new) or from second-time use (PCT-old) styroblocks so the trial consisted of four treatments (PSB, PCT-new, PCT-old, and Vapo). A splitplot design was created with the stock type being the main factor, seedlot being the split-plot factor, and with three replicates of each stock type $\times$ seedlot combination ( 12 seedlings per replicate, 72 seedlings per stock type). The data were analyzed accordingly. Since the intent was to excavate the seedlings after three growing seasons, a spacing of $0.5 \times 0.5 \mathrm{~m}$ was used and each stock type $\times$ seedlot replicate was randomly situated within a $14 \times 7 \mathrm{~m}$ space of the nursery bed. The trial was left at ambient conditions for three growing seasons. The trees were then re-measured and excavated with shovels for an assessment of root systems by a student using the data for her co-operative program work term project ${ }^{5}$. Continuous variables (e.g., height and diameter at the soil level) were analyzed with the General Linear Models Procedure of the SAS (the SAS Institute, Carry, North Carolina) while the categorical-type data (e.g.,

${ }^{5} \mathrm{~J}$. McGarvie. 1995. A comparison of growth performance, root form, and stem form of lodgepole pine produced by different root pruning treatments. Dept. of Biology Co-op Program Work Term Report, University of Victoria. 
Table 2. Percentages of trees in different anchorage strength categories at destabilization and at complete uprooting for two stock types: hard-wall polystyroblock (PSB), and peat-cube germinated seedlings tested 12 years after planting on the Telegraph Rd. site near Prince George, B.C (data from Krasowski et al. 1996a). Turning moments in $\mathrm{kNm}$, lower range values in each category are inclusive.

\begin{tabular}{|c|c|c|c|c|c|c|c|c|}
\hline & \multicolumn{4}{|c|}{ Categories by destabilization } & \multicolumn{4}{|c|}{ Categories by complete uprooting } \\
\hline & $\begin{array}{c}\text { weakest } \\
<2.5\end{array}$ & $\begin{array}{c}\text { weak } \\
2.5>5\end{array}$ & $\begin{array}{c}\text { fair } \\
5>7.5\end{array}$ & $\begin{array}{l}\text { strong } \\
>7.5\end{array}$ & $\begin{array}{c}\text { weakest } \\
<5\end{array}$ & $\begin{array}{c}\text { weak } \\
5>10\end{array}$ & $\begin{array}{c}\text { fair } \\
10>15\end{array}$ & $\begin{array}{c}\text { strong } \\
>15\end{array}$ \\
\hline PSB & $17 \%$ & $36 \%$ & $22 \%$ & $25 \%$ & $17 \%$ & $55 \%$ & $22 \%$ & $6 \%$ \\
\hline PTG & $6 \%$ & $19 \%$ & $28 \%$ & $47 \%$ & $8 \%$ & $36 \%$ & $39 \%$ & $17 \%$ \\
\hline
\end{tabular}

types of root deformations, classes of stem crookedness) were analyzed using the Categorical mode (CATMOD) procedure (maximum likelihood analysis of variance), transforming the data by the Ranking Procedure, where normalization of the distribution was necessary. Seedlot effects were insignificant for all tested variables so the data were pooled across the seedlots for further analyses. At planting, the seedlings were on average $152.7( \pm 3.65) \mathrm{mm}$ tall and $2.79( \pm 0.05) \mathrm{mm}$ in RCD with no significant differences among the stock types. After three growing seasons, height increment was greatest in Vapo while RCD increment was greatest in PCT-old (Table 3). The differences in shoot and root dry weights were not statistically significant. The differences in the occurrence of root system deformations were very significant ( $\mathrm{p}$-values for stock type effects were at 0.0001 for all compared types of deformations) with Vapo having definitely fewer deformations of any kind. Interestingly, chemical pruning of roots apparently reduced only root balling but did little to reduce root twisting and swelling at the root collar. Although there was no formal evaluation of root system symmetry, it was noted after excavations that chemically root-pruned seedlings and, especially the Vapo, appeared to have more symmetrical root systems than the PSB. The visual appearance of the root systems in PCT was more desirable than that of the PSB. The former had lower incidence of balling and better distribution of lateral roots originating throughout the whole length of the nursery plug, while in the PSB the laterals grown after planting were mainly at the bottom of the plug. The frequency and severity of stem deformations were also compared. With the aid of a wooden square, the distance between the planting position in the soil and the tip of the leader was measured. This, divided by the length of the main axis gave the cosine of the lean angle from which the angle was determined. Three classes of leaning were established: a) none/little (less than $1^{\circ}$ from the vertical), b) moderate $\left(1^{\circ}-5^{\circ}\right.$, inclusive), and c) severe (more than $5^{\circ}$ ). Trees from PSB and PCT-new leaned the most. Seventy six percent of PSB and 82\% of PCT-new fell into the moderate or severe lean categories. In the PCT-old and Vapo, $42 \%$ and $39 \%$ of trees, respectively, fell into the none/slight lean category. The two pairs of planting stock were significantly different from each other. Numbers of stem curvatures were counted and their severity arbitrarily categorized as none/slight, moderate, and severe but the stock types did not differ significantly in this respect. This indicated that the presence of root system deformations did not necessarily result in greater incidence of stem curvatures. Assuming that stem curvatures result at least to some extent from leaning due to inadequate anchorage, it was concluded that, on this site, the presence or absence of root deformations did not affect the anchorage of trees in any planting stock enough to produce curved stems. However, the trees were in the ground for only three years and the differences among the stock types in the numbers of leaning trees could result in
Table 3. Mean height and RCD increments over three growing seasons for lodgepole pine stock types compared in a trial at Red Rock Research Station and percentages of trees with various root deformations in each stock type. Means and percentages represent a sample of 72 trees per stock type (seedlots and replicates are pooled). Means and percentages in individual rows marked with the same letter are not significantly different from each other at $\alpha=0.05$ ) as determined by pair-wise comparisons of stock types made in the GLM and CATMOD procedures of the SAS for the continuous and categorical-type data, respectively

\begin{tabular}{lcccc}
\hline & \multicolumn{4}{c}{ Stock type } \\
Variable & PSB & PCT-new & PCT-old & Vapo \\
\hline Height increment (mm) & $522 \mathrm{a}$ & $524 \mathrm{a}$ & $590 \mathrm{~b}$ & $651 \mathrm{c}$ \\
RCD increment (mm) & $14.1 \mathrm{a}$ & $15.4 \mathrm{a}$ & $16.9 \mathrm{~b}$ & $14.9 \mathrm{a}$ \\
Root systems without & $0 \mathrm{a}$ & $1 \mathrm{a}$ & $0 \mathrm{a}$ & $33 \mathrm{~b}$ \\
$\quad$ deformities (\%) & & & & \\
Root balling (\% trees) & 42 & 29 & 24 & 21 \\
Root twisting (\% trees) & $99 \mathrm{a}$ & $97 \mathrm{a}$ & $96 \mathrm{a}$ & $4 \mathrm{~b}$ \\
Swelling at the root collar & $90 \mathrm{a}$ & $97 \mathrm{a}$ & $97 \mathrm{a}$ & $53 \mathrm{~b}$ \\
\hline
\end{tabular}

Note that the data for root balling could not be well fitted into the CATMOD procedure; hence, this deformation was not separately analyzed.

the development of crooked stems in the future, if judging by what is described in the next section.

The presence of root deformations in the trial discussed above did not correspond to any significant differences in growth performance in a large trial involving the same stock types (except, only new PCT containers were used) established 1992 on two sites near Prince George. A completely randomized block design consisting of four blocks on each site was used. Each block contained randomly ordered rows of 80 trees of each stock type. One site was located on a fine-textured, poorly drained lacustrine soil, the other on a well-drained sandy loam. The last measurement on this site in 1999 (eight growing seasons after planting) showed no significant differences in height and stem diameter (measured at the ground level) due to stock type and the site, and no significant stock type $\times$ site interactions were found for these variables. However, significant differences in survival and number of crooked stems were found. Site $\times$ stock type effect ( $p$ 0.02) on survival was caused by the lower survival of PCT on the fine-textured soil site than on the sandy-loam site (Table 4). The reasons of the lower survival of PCT seedlings are not known. Using the same arbitrary classification of stem crookedness as in the trial described above, the distribution of trees into the crookedness classes was tested using the CATMOD procedure of the SAS in accordance with the experimental design. It showed a significant effect of the site (p 0.0001) and stock type ( $\mathrm{p}$ 0.006). There was no significant site $\mathrm{x}$ stock type interaction because all stock types had a greater proportion of crooked trees on the fine-textured soil site than on the sandy-loam site. The PSB had generally more stem deformations than the other two stock types (Table 4). However, PCT and Vapo (Table 4) were 
Table 4. Seedling survival and stem deformations (curvatures) in trees on two forest sites near Prince George, B.C.-Site 19 is a site with a fine-textured, clayish soil, site 24 is a well-drained sandy-loam site. Arbitrarily defined stem deformation classes are none/light (N/L), moderate (MOD), and severe (SEV) as judged by visual assessment. The results are based on 320 trees per stock type/site to the total of 1920 observations. Values in deformity classes are percentages of seedlings surviving at the end of the eighth growing season.

\begin{tabular}{|c|c|c|c|c|c|c|c|c|}
\hline \multirow[b]{2}{*}{$\underline{\text { Sock }}$} & \multicolumn{4}{|c|}{ Site 19} & \multicolumn{4}{|c|}{ Site 24} \\
\hline & Survival & $\mathrm{N} / \mathrm{L}$ & MOD & SEV & Survival & $\mathrm{N} / \mathrm{L}$ & MOD & SEV \\
\hline PSB & $91.2 \%$ & $43.5 \%$ & $42.5 \%$ & $14.0 \%$ & $88.4 \%$ & $73.8 \%$ & $24.7 \%$ & $1.5 \%$ \\
\hline PCT & $73.1 \%$ & $81.2 \%$ & $16.7 \%$ & $2.1 \%$ & $87.8 \%$ & $84.3 \%$ & $14.9 \%$ & $0.8 \%$ \\
\hline Vapo & $93.1 \%$ & $79.5 \%$ & $18.7 \%$ & $1.8 \%$ & $94.7 \%$ & $90.1 \%$ & $9.3 \%$ & $0.6 \%$ \\
\hline
\end{tabular}

also found to be significantly different from each other. The effects of root system development on the occurrence of stem deformations can be only suspected but the connection between stem curvatures and anchorage strength is likely if leaning of the trees is taken as an additional indicator. Overall, PSB leaned the most. Using the same classes of lean as described before, this stock type was significantly different than the other two (stock type effect 0.0001 ) with only $11 \%$ of trees in the none/slight leaning class. The PSB had almost all trees leaning on the fine-texture soil and $36 \%$ of them were in the severe lean class. The PCT had $51 \%$ and Vapo 57\% of trees (across both sites) in the none/slight lean class while the majority of the remaining trees in these stock types were in the moderate lean class. Generally, more trees leaned on the finetexture soil than on the sandy loam producing a significant site effect (p 0.002). It can be concluded that chemical pruning improved the stability, as evidenced by the reduced leaning of trees, compared to standard PSB stock. It also reduced the number of stem curvatures, although not as much as mechanical pruning did. This outcome is better for chemically pruned seedlings than what could be expected from the detailed seedling analyses performed in the previously described small trial.

\section{Root System Size at Planting, Its Hydraulic Conductivity and Seedling Performance after Planting}

Many papers have reported a positive relationship between the root system size at planting and the growth after planting. Examples of this can be found in Rose et al. (1991a, b) in which seedlings of bare-root Douglas-fir (Pseudotsuga menziesii Mirb. Franco) and ponderosa pine (Pinus ponderosa Dougl. ex P. \& C. Laws.) with larger root system volumes grew more during two seasons than those with smaller volumes. These authors suggest that root volume could be a useful criterion for grading seedlings. Grossnickle et al. (1991) suggest using root surface area as a seedling quality attribute in the integrated seedling quality assessment system developed by these authors. Some interesting and important topics can be considered in the context of these reports. A large root system area may be indicative of its large absorptive potential (Thompson 1985) but the absorption or water and nutrients from the soil and the ability of a root system to efficiently conduct the absorbed water must be viewed in the context of the anatomy of individual roots (Tyree and Karamanos 1981). Unfortunately, the relationship between root developmental anatomy in conifers and the uptake of water and nutrients from the soil is poorly understood (Peterson et al. 1999). Roots vary in the developmental advancement along their lengths and it is unreasonable to assume that each portion of a root contributes equally to the uptake of water and nutrients. To complicate things even more, root systems of many conifers develop distinctly different root types. Such root systems are referred to as being heterorhizic (Wilcox 1954). The heterorhizy has been reported in many species of the Pinaceae family but it may not characterize root systems of all conifers. Wilcox (1962) reported that root systems of incense cedar (Libocedrus decurrens Torr.) have no heterorhizic root systems and it is possible that this characterizes the Cupressaceae family. Hence, not only a variation in the uptake and solute transport capabilities may exist among different individual roots and their portions but these characteristics may vary among root systems of different species. Based on the surface area rather than the length, MacFall et al. (1991) show fine roots of loblolly pine (Pinus taeda L.) seedlings being more efficient in absorbing water than the large laterals. They also note that even older portions of roots with advanced secondary development absorb water. A root system does not require the presence of white root tips to uptake water (Kramer 1947) and even root systems of dormant seedlings with all roots brown to the tip are capable of efficient water uptake at temperatures barely above freezing (Krasowski et al. 1996b). Why then should we expect seedlings with larger root systems at planting to survive and perform better than those with smaller root systems if we have not been able to comprehend the possible functional variation among different root types and their developmentally distinct portions? As noted by Rose et al. (1991), bare-root seedlings with large root systems usually also have thicker stems so it is possible that the perceived effect of the size of a root system on growth performance may simply reflect the overall vigour of the plant. If so, then the measurement of a root system's size could be useful as an indicator of seedling quality but it may not necessarily explain the differences in growth performance by the alleged relation of the root system size at planting to its absorptive and conductive properties.

Measurements of root system size may not be very useful for seedlings in which the morphology of the root system reflects modifications of its development in the nursery caused by container type and size and by root pruning. An experiment comparing different types of nursery stock for the ability of their root systems to conduct water at different times after planting was made on seedlings of white spruce (Picea glauca Moench. Voss.). This experiment used three already introduced stock types of 1+0 spruce: 1) PSB 415B, 2) PCT 415B, and 3) Vapo. The study was reported by Krasowski and Owens (2000) and had the following objectives: a) to evaluate how hydraulic properties differ in root systems of different sizes and in different types of nursery stock and how these properties change during the first weeks after planting, and b) to determine if vigorous root growth shortly after planting results in better performance of seedlings or even in greater expansion of the root systems during the first post-planting season. The study had two components. The growth performance of the three stock types 
was tested after lifting, freezer storing, and planting the seedlings on two forest sites. The stock types did not differ in height and ground-level diameter immediately after planting but three seasons later Vapo seedlings grew significantly more in height and stem diameter on both sites as detected by the repeated-measures ANOVA showing significant effects of stock type over time for height ( $\mathrm{p} 0.03$ ) and stem diameter ( $\mathrm{p}$ 0.02) (Krasowski and Owens 2000). Detailed physiological and morphological measurements were made on seedlings from the same stock types planted into 4L plastic pots filled with nursery soil. The seedlings were planted together with the pots into a nursery bed and left at ambient conditions with samples (eight seedlings per stock type) collected during the second week after planting and another sample (16 seedlings per stock type) collected between the fifth and seventh week after planting (see the original paper for details). Hydraulic properties of the roots were measured with root pressure probes (Steudle 1993) while the recovered root systems were washed, scanned, and then the images were analyzed using the WinRhizo software (Regent Instruments, Quebec).

The four graphs shown in Fig. 1a-d are arranged such that the three upper bars on each graph represent stock type means of the samples collected during the first sampling period while the lower three bars of each pair represent the means determined during the second sampling period. Results from the first sampling time reveal that root systems of Vapo were smaller than those of the other stock types whether considering the length (Fig. 1a), root surface area (Fig. 1b) and the number of root tips (Fig. 1c). The lack of significant differences between the PCT and PSB, especially in root tip numbers, indicates that chemical root pruning during nursery culture was not very effective. Hydraulic properties of the three stock types measured at that time do not differ significantly despite quite large variation among the means. Note that Fig. 1d shows mean flux of water (volume) per unit of time at a given hydrostatic pressure (induced with a pressure probe). The PCT stock has the greatest mean flux while the means of the PSB and Vapo are much closer to each other. The lack of significant differences among the stock types seems to reflect a large variation among individual root systems in all stock types and a larger sample size is likely required to improve the accuracy of this comparison. However, the pressure-probe measurements are time-consuming, the devices are costly, and this puts a limit on a number of samples that can be handled within a specified time frame. Still, the results show that the relationship between root system size and its capacity to conduct water is neither simple nor straightforward. Typically, root (or root system) hydraulic characteristics are expressed as the so-called hydraulic conductivity (this is obtained by dividing the flux of water by the root surface area) that reflects the speed at which water can travel through the roots at a given pressure induced by the pressure probe (normally, a negative pressure would be exerted by the pulling force of the transpiration) rather than by the flux of water through the root system described above. The calculation of hydraulic conductivity assumes an equal conductivity of each and every portion of the root system, which is an unrealistic assumption. Nonetheless, it is a convenient expression of the relationship between the size of a root system and its capacity to conduct water so it is useful for the particular purpose discussed here. The means of hydraulic conductivity $\left(\mathrm{m} \mathrm{s}^{-1} \mathrm{MPa}^{-1} \times 10^{-8}\right)$ at the first sampling time are 3.20, 1.98, and 2.29 (standard error of least square means of 0.48) for PCT, PSB, and Vapo, respectively and they are not significantly different from each other indicating that root system size just after planting has no significant effect on the hydraulic conductivity.

Now, let us consider how the root systems and their hydraulic properties changed in another month after planting. The root systems of PSB and PCT increased in size (length, surface area, and root tip numbers) significantly during that time (Figs. $1 \mathrm{a}-\mathrm{c})$ and the differences in root system expansion from time 1 to time 2 are significant for both stock types but not significant if compared between the stock types. Vapo root systems expanded very little from time 1 to time 2 (Figs. 1a-c). The only significant difference between the sampling times is the increase in root surface area, but even this is much smaller than in the other stock types tested. The differences in root system sizes between the two measuring times obviously reflect the growth of roots and initiation of new roots over that time period and, interestingly, the differences among the stock types in root growth do not correspond well with changes to their hydraulic properties (Fig. 1d). The differences in water flux among the three stock types at time 2 measurement are still not statistically significant but the increase in water flux in Vapo between measurements at time 1 and time 2 is significant (stock type $\times$ measurement time effect $\mathrm{p} 0.03$ ), despite the small increase in root system size attributes. The lack of a relationship between the sizes, the extents of expansion during the first post-planting weeks, and abilities of root systems to conduct water was even more obvious when hydraulic conductivities at time 2 were compared instead of the flux of water through the root system. The means of hydraulic conductivity were 1.87 , 1.93, and 3.88 (standard error of least square means 0.35 ) for PCT, PSB, and Vapo, respectively, the Vapo being significantly different from the other two stock types. Therefore, the capacity of the root systems of Vapo seedlings increased with time after planting while it declined or changed little in PSB and PCT, despite a significant root system expansion in the two latter stock types. This shows that not only the relationship between the capacity to conduct water and the root system size in seedlings is disproportional, but that the expansion of the root system after planting does not necessarily result in its increased capacity to conduct water.

Another question asked in this study (Krasowski and Owens 2000) was whether the small root systems and their slow initial expansion in the Vapo would compromise the seedling growth and root system development during the first growing season after planting. To this end, 16 seedlings of similar sizes (four per container) of each stock type were planted into large, 64L wooden boxes filled with nursery soil and topped $(4 \mathrm{~cm})$ with an organic mix (compost, decomposed bark, and peat). The whole boxes were buried in the nursery soil (note that water drainage from these and from all other pots used in these experiments was ensured) for the whole growing season after which the boxes were recovered and the seedlings were analyzed in detail. Despite the initially smaller root systems, at the end of the first growing season Vapo seedlings had very significantly greater final height, RCD, total biomass, root system biomass, projected leaf area, the length and surface area of the roots, and the number of root tips. Since this trial was made in the absence of competing vegetation, hence allowing for unhindered expression of growth potential at given conditions, the conclusion was that the size of the root system at planting and the initial expansion 
a) Length of roots $(\mathrm{mm})$

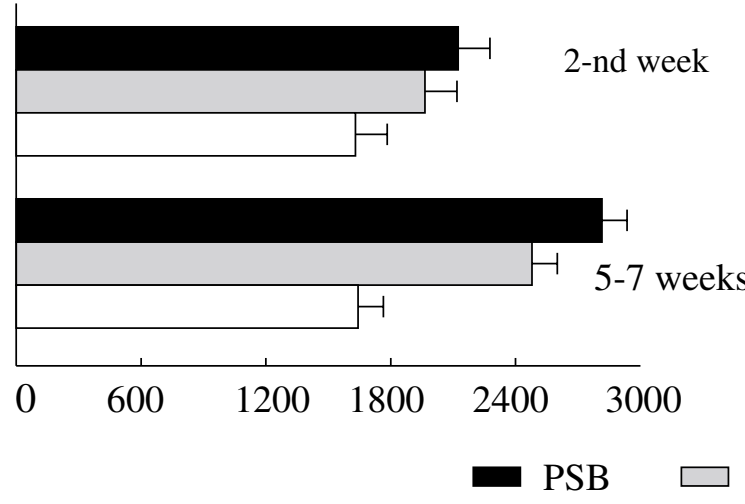

c) Number of root tips

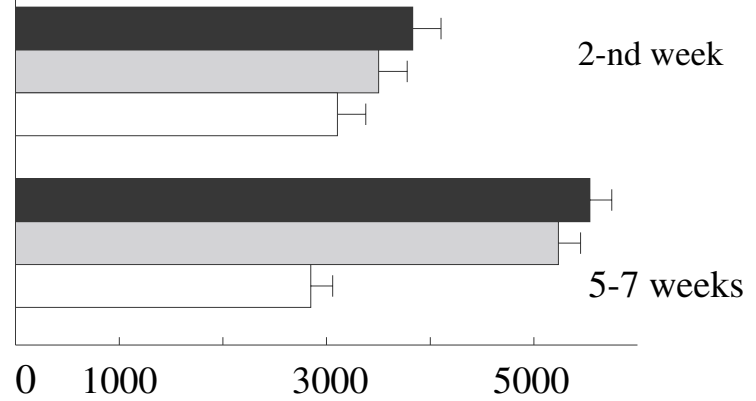

b) Surface area $\left(\mathrm{cm}^{2}\right)$

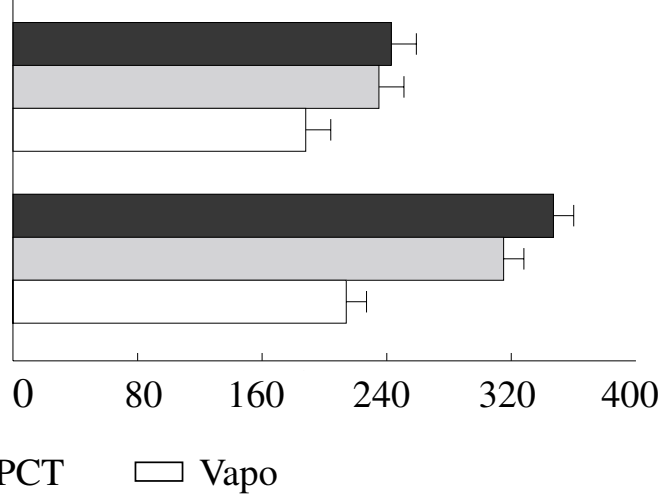

d) Water flux $\left(\mathrm{m}^{3} \mathrm{~s}^{-1} \mathrm{MPa}^{-1} \times 10^{-12}\right)$

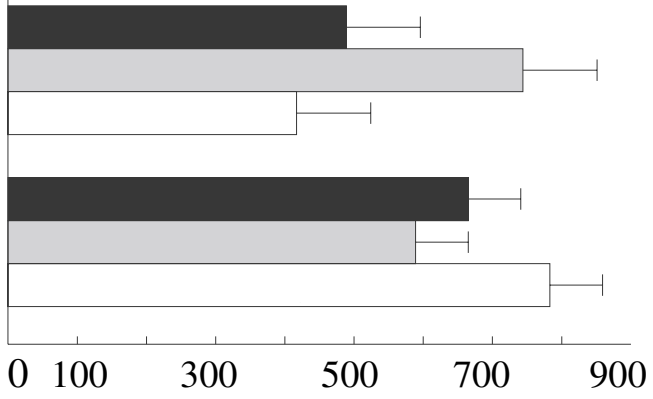

Fig. 1 a-d. Changes in root length (Fig 1a), root surface are (Fig. 1b), numbers of root tips (Fig. 1c), and pressure-probe induced water flux through the root system (Fig. 1d) between measurements taken during the second and the fifth/sixth week after planting of white spruce seedlings with mechanically pruned roots (Vapo), non-pruned (PSB) and chemically pruned (PCT) roots. Shown are means and their standard errors (capped bars). Data from Krasowski and Owens 2000.

of the root systems after planting did not correspond to the growth potential of tested seedlings and was not indicative of a longerterm root system development.

To put the above in the right perspective, I am not saying that the growth of roots after planting is irrelevant to the successful establishment and growth performance of planted seedlings. Many years ago, Stone (1955) postulated that the survival of planted seedlings depended on their ability to produce new roots. The root growth capacity test (RGC) is based on that notion but as much as the test may be useful for detecting batches of unhealthy stock prior to planting (see Sutton 1990), RGC does reliably predict growth performance (Simpson and Ritchie 1997) which further reinforces the idea that predictions of the growth performance based on the early patterns of root system expansion can be misleading. Brisette and Chambers (1992) show that leaf water potential as well as leaf conductance increase linearly with increasing new root growth. This may reflect the increase in the volume of the soil ramified by the new roots and better contact between the roots and soil, and not necessarily the ability of the root system to conduct water. It does not mean that root systems with greater volume or surface area at planting are better able to absorb and conduct water than those with smaller root systems. Hence, measuring the root system size as a seedling quality criterion has a dubious value, except when it leads to the elimination of seedlings with abnormal- ly poor root systems. It makes sense to evaluate the usefulness and value-for-money of proposed seedling quality tests before embarking on costly venues. If the tests are based on alleged relationships between morphology and physiology, check if such assumptions are reasonable and if and how they have been disputed. In my opinion, the exact relationship between preplanting root system size and its water and nutrient uptake potential remains obscure.

The results of the study discussed above support the notion that, in a long run (although not immediately after planting), good root growth correlates well with seedling growth performance on forest sites and under no-competition conditions. Planting seedlings with pruned root systems will stimulate root growth and allow the tree to put its roots where it wants them to be rather than where the planter places them. The size of the root system and the initial growth of roots may not be critical to seedling survival when moisture availability is adequate but it may be if severe drought occurs soon after planting. This may relate more to the positioning of the roots in the soil profile than to the ability of the roots to absorb and conduct water. Short root systems would be placed in the uppermost soil portion that is most prone to drying. It has been noticed in another study that the survival of the Vapo stock (white spruce) planted just before severe drought was somewhat lower than that of the PSB 415 seedlings whose long roots were placed much deep- 
er in the soil. However, the surviving Vapo grew eventually better than the PSB (unpublished observations). One could argue that symptoms of drought stress observed after root wrenching in the nursery (for example, see Hipps et al. 1999) testify to the direct relationship between root surface area and the ability of the root system to uptake and/or conduct water. It must be realized that wrenching injures the roots, rapidly reduces the already-established in the soil root system, leaving the plant mostly with the older and woodier root portions, and that it may loosen the contact between the soil and the root system remaining after wrenching. This is different from what happens at planting where the root system is yet to establish itself in the soil. From my studies, I conclude that hydraulic properties of heterorhizic root systems are not directly related to the total length of roots in a root system, its surface area, the number of root tips, and the extent (or vigour) of its early growth. We still need to better understand the relationship between root structure and their functioning in the absorption and conduction of water.

\section{Growth of Roots in Different Soil Substrates With and Without Controlled-release Fertilizer}

Finally, I briefly discuss a study intended to determine how roots of different white spruce stock types grow when the root system is split between the mineral and organic soil substrates. Thirty-two 1+0 seedlings (16 PSB 415B and 16 Vapo) were planted into $33 \mathrm{~L}$ volume pots split vertically in half to create two compartments. One of the compartments in each pot was filled with sandy loam (mineral compartment), the other one (organic compartment) with $15 \mathrm{~cm}$ thick layer of organic mix (compost, peat, decomposed bark) on top of $10 \mathrm{~cm}$ of coarse masonry sand to improve drainage. Both compartments had bottom holes lined with a fabric mesh providing drainage but preventing the roots from leaving the pots. Taproots are typically air-pruned during the nursery culture. The root system of each seedling was divided approximately in half into each compartment at planting, then the pots together with the seedlings were buried into the nursery soil and kept at ambient conditions until the end of the growing season (see Krasowski et al. 1999 for more details). At planting, a small package containing $9 \mathrm{~g}$ of controlled-release fertilizer (26-126) N-P-K ${ }^{6}$ was placed according to label instructions into either the mineral or organic compartment or to none of the compartments creating two stock type $x$ three fertilizer treatment combinations. Five seedlings per stock type had the fertilizer in the mineral compartment, five in the organic compartment, and six seedlings received no fertilizer. After a season of growth the pots were recovered, seedlings were removed and subjected to very detailed analyses including above- and below-ground morphological measurements, assessment of ectomycorrhizal colonization of the roots (also done on a sample taken before planting), and foliar elemental analysis. Samples of the growing media were chemically analyzed before planting. Details are in Krasowski et al. (1999) but here is a summary. Fertilizer improved above-ground growth of both stock types, increased foliar concentrations of $\mathrm{N}$ and $\mathrm{P}$ but stimulated bud reflush, especially when the bag was placed into the min-

${ }^{6}$ Reforestation Technologies International, Salinas, California. eral soil. Unfertilized PSB seedlings had the fewest roots in either compartment while unfertilized Vapo seedlings had significantly more root length, surface area, and, especially, root tip numbers in the mineral than in the organic compartment. Unfertilized Vapo also had significantly more $P$ in current-year foliage than unfertilized PSB. Generally, in absence of fertilizer, root growth was less in the organic than in the mineral soil. Addition of fertilizer had different effects on root system development in each of the stock types. In Vapo, it decreased root proliferation (fewer root tips) but increased the total length and diameter of roots. In PSB, the initiation of new roots was stimulated consequently increasing the total root length and surface area. The effect of fertilizer placement was such that, if placed into the mineral compartment, it significantly affected root development in that compartment only. When placed into the organic compartment, root development in both compartments was affected. This suggests a preferential resource allocation to the portion of the root system in the mineral soil. It was noted that many roots recovered from the organic compartments (especially if unfertilized) were shrivelled and appeared degenerating while those in the mineral compartments were generally healthy looking roots. There were also differences in ectomycorrhizal colonization of roots in different compartments but the fertilizer had no effect on this. All root systems in both stock types had ectomycorrhizae on their roots before planting without any artificial inoculation during nursery growth. Except for one morphotype (Cenococcum) that was found only after planting and mostly on roots in the mineral soil, all other morphotypes were present on roots at the end of nursery growth. But, the relative abundance of different morphotypes changed after planting. In PSB, Telephora was the most abundant morphotype in the nursery while it was E-stain that was dominant in Vapo. After planting, Telephora receded and Estrain was the main morphotype in both stock types suggesting that at least some mycorrhizae developed in the nursery may be of little importance after planting and are replaced by other fungi. Generally, Vapo had greater percentage of root tips colonized by ectomycorrhizae than PSB and roots from mineral compartments had significantly more root tips colonized by mycorrhizal fungi than those from the organic compartments.

One may wonder about the relevance of a study set up in this way to what normally happens on forest sites. True enough, the substrates used in this study, especially the organic substrates, are not typical of forest soils. The arrangement of the substrates relative to the positioning of roots in them does not resemble what normally happens at planting. Still, the study suggests that organic substrates may not be the preferred medium for roots to develop in. Organic components of forest soils vary in their composition, thickness, extent of decomposition, etc., and there is no easy way to generalize about them from a study involving any one particular type of organic material or a mix. The importance of understanding the effects of soil substrates on root system development comes to mind when considering different planting practices such as planting in the so-called duff. This matter is discussed in a research note (Krasowski and Elder 2000) bringing up evidence from the literature that physical properties of many organic substrates are not ideal for root development. In some situations, the duff planting may be acceptable or even beneficial if it places the seedling higher in a microsite than scraping the duff would but in other situations, especially on dry sites, duff planting may compromise seedling survival. 
In my opinion, the detrimental effects of the organic compartment on the growth and condition of roots and on mycorrhizal development likely resulted from unfavourable physical characteristics associated with that medium, especially the poorer aeration, lower heat conductance, and different moisture retaining and conducting properties than those of the mineral soil (see Krasowski and Elder 2000 for discussion of the topic).

\section{Conclusions}

Improvements to the design of containers and to the handling of the stock during its nursery growth have been made and some problems seen at early stages of developing the containerized seedling production in western Canada have been successfully alleviated. From what I have seen and researched, I believe that the planting stock presently produced in hard-wall containers is of acceptable quality. There is always room for improvement, but it does not seem likely to me that we will see massive losses in planted forest stands because of their poor stability resulting from nursery culture. Burdett et al. (1986) estimated that about a third of lodgepole pine plantations in the southern interior of B.C. suffered from instability problems but this estimate may be excessive and needs to be re-evaluated for later-established plantations, especially those planted with chemically pruned stock. Chemical root pruning might have helped resolve some of the instability problem. The troubles with stability of pines develop mainly on moist, fine-textured soils, and sites with such soils should not be planted to pines in the first place. The importance of proper choice of species and stock types best suited for the requirements of particular sites cannot be underestimated. Likewise, the work on developing better stock types, stock culture, and planting techniques should not be abandoned. It seems to me that the support for research on stock production and the establishment of forests by tree planting has faded over the recent decade. There are certainly more pressing issues requiring a greater effort and investment of resources but we should not be satisfied with the status quo in our knowledge about the stock production and forest establishment by tree planting. Many trials established during the last three decades are now available for research. This allows determining longer-term effects of factors originally intended for evaluation when the trials were established. It may be wise to take advantage of such opportunities.

\section{Disclaimer}

Trade names and product manufacturers are mentioned for informative purposes only. The containers used in the described studies are considered to be representative of a container type only and their choice for the research should not be interpreted as an evaluation or comparison of particular brands.

\section{References}

Brazier, D. 1991. A review of changes in B.C. forest seedlings market during the period of 1986-1991. In F.P. Donelly and H.W. Lussenberg (eds.). Proc. 1991 For. Nurs. Assoc. of B.C., Meeting in Prince George, B.C. pp. 37-42.

Brisette, J.C. and J.L. Chambers. 1992. Leaf water status and root system water flux of shortleaf pine (Pinus echinata Mill) seedlings in relation to new root growth after transplanting. Tree Physiology 11: 289-303.

Burdett, A.N. 1978. Control of root morphogenesis for improved mechanical stability of container-grown lodgepole pine. Can. J. For. Res. 8 : $483-486$.
Burdett, A.N. 1979. Juvenile instability in planted pines. Ir. For. 36: 36-47.

Burdett, A.N. 1981. Box pruning the roots of container grown seedlings. In J.B. Scarrat, C. Glerum and C.A. Plexman (eds.). Proceedings of Canadian Containerized Tree Seedling Symposium, Sept. 14-16, 1981, Toronto, Ont. pp. 203-206. Ontario Ministry of Natural Resources and Canadian Forest Service, Sault St. Marie, Ont. Can-Ont. Joint For. Res. Comm. Symp. Proc. 00-P-10.

Burdett, A.N., H. Coates, R. Eremko and P.A.F. Martin. 1986. Toppling in British Columbia lodgepole pine plantations: significance, cause, and prevention. For. Chron. 62: 433-439.

Clarke, C. and R. Winter. 1986. Lodgepole pine root form trial Jack Fire final report. B.C. Min. For. Silv. Br., Victoria, B.C. RMX 7901. Coutts, M.P. 1983. Root architecture and tree stability. Plant Soil 71: 171-181.

Coutts, M.P., C. Walker and A.C. Burnand. 1990. Effects of establishment method on root form of lodgepole pine and Sitka spruce and on the production of adventitious roots. Forestry 63:143-159. Deans, J.D. and E.D. Ford. 1983. Modeling root structure and stability. Plant Soil 71: 189-195.

Fraser, A.I. 1962. The soil and roots as factors in tree stability. Forestry 35: 117-127.

Grossnickle, S.C., J.A. Major, T.J. Arnott and V.M. LeMay. 1991. Stock quality assessment through an integrated approach. New Forests. 5: 77-91.

Hipps, N.A., K.H. Higgs and L.G. Collard. 1999. Effects of root wrenching on the growth and water relations of Prunus avium and Castanea sativa in nursery beds and after outplanting. Can. J. For. Res. 29: 696-704. Kramer, P.J. 1947. Absorption of water through suberized roots of trees. Plant Physiol. 21: 37-41.

Krasowski, M. J. and R. J. Elder. 2000. Opportunities to improve reforestation success. Extension Note \#43, B.C. Min. For. Res. Program, Victoria, B.C. $15 \mathrm{p}$.

Krasowski, M.J, C.B.D. Hawkins and H. Coates. 1993. The relationship between root formation and mechanical stability. In Proc. For. Nurs. Assoc. of B.C., Penticton Meeting, Sept. 1992. pp.107-114.

Krasowski, M.J., C.B.D. Hawkins, H. Coates and P.K. Ott. 1996a. Static tests of lodgepole pine stability in the central interior of British Columbia. Can. J. For. Res. 26: 1463-1472.

Krasowski, M.J., C.B.D. Hawkins, H. Coates and P.K. Ott. 1997. Static tests of lodgepole pine stability in the central interior of British Columbia [erratum]. Can. J. For. Res. 27: 618.

Krasowski, M.J., T. Letchford, A. Caputa, W.A. Bergerud and P.K. Ott. 1996b. The susceptibility of white spruce seedlings to overwinter injury and their post-injury field responses. New Forests 12: 261-278.

Krasowski, M.J. and J.N. Owens. 2000. Morphological and physiological attributes of root systems and seedling growth in three different Picea glauca reforestation stock. Can. J. For. Res. 30: 1669-1681.

Krasowski, M.J., J.N. Owens, L.E. Tackaberry and H.B. Massicotte. 1999. Above- and below-ground growth of white spruce seedlings with roots divided into different substrates with or without controlled-release fertilizer. Plant Soil 217: 131-143.

Lindstöm, A. 1990. Stability in young stands of containerized pine (Pinus sylvestris). Translation from Internal Report \#57, Swed. Univ. Agric. Sci. Dept. For. Yield Res., Garpenberg, Sweden.

Lines, R. 1980. Stability of Pinus contorta in relation to wind and snow. In Pinus contorta as an exotic species. Proc. IUFRO Meeting, 1980. Swed. Univ. Agric. Sci. Dept. For. Genet. Res. Note 30: 209-219. Grapenberg, Sweden.

MacFall, J.S., G.A. Johnson and P.J. Kramer. 1991. Comparative water uptake by roots of different ages in seedlings of loblolly pine (Pinus taeda L.). New Phytol. 119: 551-560.

Parviainen, J. and L. Tervo. 1989. A new approach for production of containerised coniferous seedlings using peat sheets coupled with root pruning. Forestry (Suppl.) 62: 87-94. 
Persson, P. 1978. Some possible methods of influencing the root development of containerized tree seedlings. In E. Van Eerden and J.M. Kinghorn (eds.). Proc. Root Form of Planted Trees Symp. pp. 295-300. B.C. Min. For./Can. For. Serv. Joint. Rep. 8.

Persson, P. 1982. Instability in plantations - extent, causes, and possible remedies. In H. Hulten, H. (ed.) Root Deformation of Forest Tree Seedlings, Proc. of Nordic Symp. pp. 11-20. Swed. Univ. Agric. Sci. Dept. For. Yield Res. Rep. \#11.

Peterson, C.A., D.E. Enstone and J.H. Taylor. 1999. Pine root structure and its potential significance for root function. Plant Soil 217: 205-213. Rose, R., J. Atkinson and T. Sabin. 1991a. Root volume as a grading criterion to improve field performance of Douglas-fir seedlings. New Forests 5: 195-209.

Rose, R., J. Gleason, J. Atkinson and T. Sabin. 1991b. Grading ponderosa pine seedlings for outplanting according to their root volume. W.J.A.F. 6: 11-15.

SAS Institute Inc. 1990. SAS/STAT User's Guide, Version 6, Fourth Edition. SAS Institute Inc., Cary, NC.

Simpson, D.G. and G.A. Ritchie. 1997. Does RGP predict field performance? A debate. New Forests 13: 253-277.

Steudle, E. 1993. Pressure probe techniques: basic principles and application to studies of water and solute relations at the cell, tissue, and organ level. In J.A.C. Smith and H. Griffith (eds.). Water deficits: plant responses from cell to community. pp. 5-36. Bios Sci. Publishers, Oxford.
Stone, E.C. 1955. Poor survival and the physiological condition of planted stock. For. Sci. 1: 90-94.

Sutton, R.F. 1990. Root growth capacity in coniferous forest trees. Hort. Sci. 25: 259-266.

Thompson, B.E. 1985. Seedling morphological evaluation - what you can tell by looking. In M.L. Duryea (ed.). Evaluating seedling quality: principles, procedures, and predictive abilities of major tests. pp. 59-72. Forest Resources Lab., Oregon State Univ., Corvallis.

Tyree, M.T. and A.J. Karamanos. 1981. Water stress as an ecological factor. In J. Grace, E.D. Ford and P.G. Jarvis (eds.). Plants and their atmospheric environment. pp. 237-261. Blackwell Scientific, Oxford. Wenny, D.L. and R.L. Woollen. 1989. Chemical root pruning improves the root system morphology of containerized seedlings. New Forests 2: 111-118.

Wilcox, H. E. 1954. Primary organization of active and dormant roots of Abies procea. Amer. J. Bot. 41: 812-821.

Wilcox, H. E. 1962. Growth studies of the root in incense cedar, Libocedrus decurrens. II. Morphological features of the root system and growth behavior. Amer. J. Bot. 49: 237-245.

Winter, R. and S. Low. 1990. Manual and chemical root pruning of lodgepole pine PSB 211 stock. B.C. Min. For. Silv. Br. Interim Rep. SX86125Q. 